\title{
APROXIMAÇÃO DO CT ÀS ESCOLAS PÚBLICAS DO ENTORNO DO PICI POR MEIO DO ENSINO DA TOPOGRAFIA
}

Ilana Tôrres Pontes - ilanatorrespontes@gmail.com

Departamento de Engenharia de Transportes

Rua Professor Armando Farias, 713, Pici

60020-181 - Fortaleza - Ceará

Karyna Stefhany Jorge Cunha - cunhakaryna@gmail.com

Departamento de Engenharia de Transportes

Rua Professor Armando Farias, 713, Pici

60020-181 - Fortaleza - Ceará

Nadja Glheuca da Silva Dutra-nadja@det.ufc.br

Departamento de Engenharia de Transportes

Rua Professor Armando Farias, 713, Pici

60020-181 - Fortaleza - Ceará

Resumo: O projeto de extensão "Engenharia na Escola" foi criado com o intuito de levar para o Centro de Tecnologia alunos de escolas públicas do entorno do Campus do Pici, fazendo com que estes pudessem conhecer um dos campi da Universidade Federal do Ceará. Esta aproximação se dá por meio da disciplina de Topografia, do curso de Engenharia Civil, visto que esta aborda conteúdos de Matemática e Geografia, aprendidos durante a vida escolar. Duas escolas foram selecionadas no ano de 2019, sendo formadas três turmas com os alunos interessados em participar do minicurso "Noções de Topografia e suas Aplicações". Inicialmente uma palestra foi realizada em cada escola, na qual foram explanados oportunidades e os cursos ofertados pela universidade, além de sua distribuição nos campi. Em seguida, são formadas as turmas para o minicurso e no qual são aplicados dois questionários, um no primeiro dia e outro no segundo, visando avaliar o conhecimento adquirido pelos participantes. Os resultados evidenciaram que os alunos conseguiram relacionar o conteúdo abordado no minicurso com os que já haviam sido estudados durante sua vida escolar, sendo assim, bem avaliado pelos participantes.

Palavras-chave: Engenharia. Aproximação. Topografia. Ensino. Extensão.

\section{INTRODUÇÃO}

A engenharia não se limita somente em estudos de matérias exatas e naturais, mas, também, a uma colaboração direta e indireta com a melhora do convívio social (DAGNINO et al., 2013). Para o engenheiro, porém, não são concedidos muitos espaços em que se discute, de forma eficaz, o significado do papel social do engenheiro frente à sociedade, dado que, em sua formação, essa questão é quase inexistente, sua missão, portanto, vai além da tecnicidade que a profissão exige. Na prática de seu ofício, os engenheiros lidam com públicos diversos de diferentes maneiras, sendo assim, a urgência para que a comunicação entre o profissional e 
a sociedade seja efetivamente criada.

A Universidade pública é pautada em três fundamentos inter-relacionados: ensino, pesquisa e extensão. A Extensão Universitária, por outro lado, facilita a formação da comunicação entre a instituição e comunidade, possibilitando o compartilhamento de conteúdos e pesquisas desenvolvidos na instituição. Segundo Nunes e Silva (2012), essa comunicação comporta-se de forma que tanto a instituição científica quanto a comunidade se beneficiariam dessa troca de conhecimentos: a Universidade entenderia culturas e valores da comunidade e a primeira, por meio desse entendimento, planejaria e executaria atividades que respeitassem as culturas e valores da comunidade. $\mathrm{O}$ futuro engenheiro, referente a essa troca, aprenderia habilidades que não são incluídas em sua grade curricular, como oratória, capacidade de liderar e trabalho em equipe.

Conforme o padrão acadêmico seguido pelos estudantes brasileiros, após o Ensino Médio, os mesmos realizam o ENEM (Exame Nacional do Ensino Médio) para ser possível ingressar em uma Instituição de Ensino Superior. Entretanto, conforme o Índice de Desenvolvimento da Educação Básica (Ideb, 2017), o índice para o ensino médio aumentou 0,1 ponto em comparação às últimas três divulgações, chegando em 3,8 , ainda embaixo da meta, 4,7. Um dos principais problemas que os professores enfrentam na educação pública é a falta de atualização de currículos e métodos utilizados, que, muitas vezes, são ultrapassados, dificultando a aprendizagem do estudante.

Além disso, passada a fase de Ensino Médio, o aluno ainda tem o desafio de escolher qual caminho irá percorrer na instituição de Ensino Superior. "Em geral, trata-se de uma escolha quando ainda o estudante não tem domínio das questões básicas em relação à futura profissão." (TOZZI, 2004). Os cursos de engenharia, por exemplo, são vistos pelos alunos de rede pública, em sua grande maioria, como difíceis de ingressar e de concluir e soma-se a isso o fato de boa parte desconhecer as atribuições dos engenheiros. Ainda, há um sentimento de que eles desconhecem as oportunidades e benefícios oferecidos pela Universidade aos discentes como: bolsas de estudo, desporto, pesquisa e extensão; oferta de infraestrutura como restaurante universitário; transporte coletivo gratuito no campus; residência universitária; dentre outras (OLIVEIRA 2018).

O estudante como produtor de saber deve estar ciente, assim como o seu professor, que ensinar não é transferir conhecimento, mas sim desenvolver métodos e práticas para a sua construção (FREIRE, 2002). Essa prática auxilia na autonomia para o desenvolvimento intelectual do aluno, que busca correlacionar conteúdos com a prática. Segundo Lewin e Lomascólo (1998), quando o estudante assume a posição de cientista ao preparar e realizar experiências, recolher dados e analisar resultados, ele estará fomentando a sua motivação, favorecendo ações como curiosidade, desejo de experimentar e da mudança, pensamento crítico, que auxiliam no processo de desenvolvimento intelectual.

Visando, então, o contato com a comunidade, representada pelas escolas de rede pública, a Universidade, procura solucionar questões envolvendo alunos de Ensino Médio, como o desconhecimento sobre benefícios e atividades que a Universidade pode oferecer, sobre a importância e atribuições dos engenheiros, intensificar as atividades extensionistas tanto na Universidade quanto nas escolas de rede pública e, por fim, conforme o artigo 35 da Lei das Diretrizes e Bases da Educação Nacional - LDB (1996), auxiliar a educação básica em uma de suas finalidades "a compreensão dos fundamentos científico-tecnológicos dos processos produtivos, relacionando a teoria com a prática, no ensino de cada disciplina".

Para tal fim, a disciplina de Topografia foi escolhida com o objetivo de salientar a importância profissional que esta tem com a Engenharia Civil, de relacionar a disciplina com conteúdos vistos no Ensino Médio como Matemática e Geografia além de materializar esses conhecimentos com a prática em campo. 


\section{METODOLOGIA}

\subsection{Escolas do Projeto}

Inicialmente, duas escolas foram selecionadas situadas próximas ao Campus do Pici, onde se localiza o Centro de Tecnologia (CT), sendo elas EEMTI Santo Afonso e a EEEP Presidente Roosevelt, a primeira de tempo integral e a última profissionalizante. Contataramse os diretores ou coordenadores das escolas para marcar um encontro e oficializar o compromisso com o projeto de extensão, na qual foi marcado o dia da palestra, segunda etapa do projeto. A Figura 1 mostra as localizações das escolas selecionadas para participar do projeto.

Figura 1 - Escolas Estaduais Selecionadas para o Estudo.

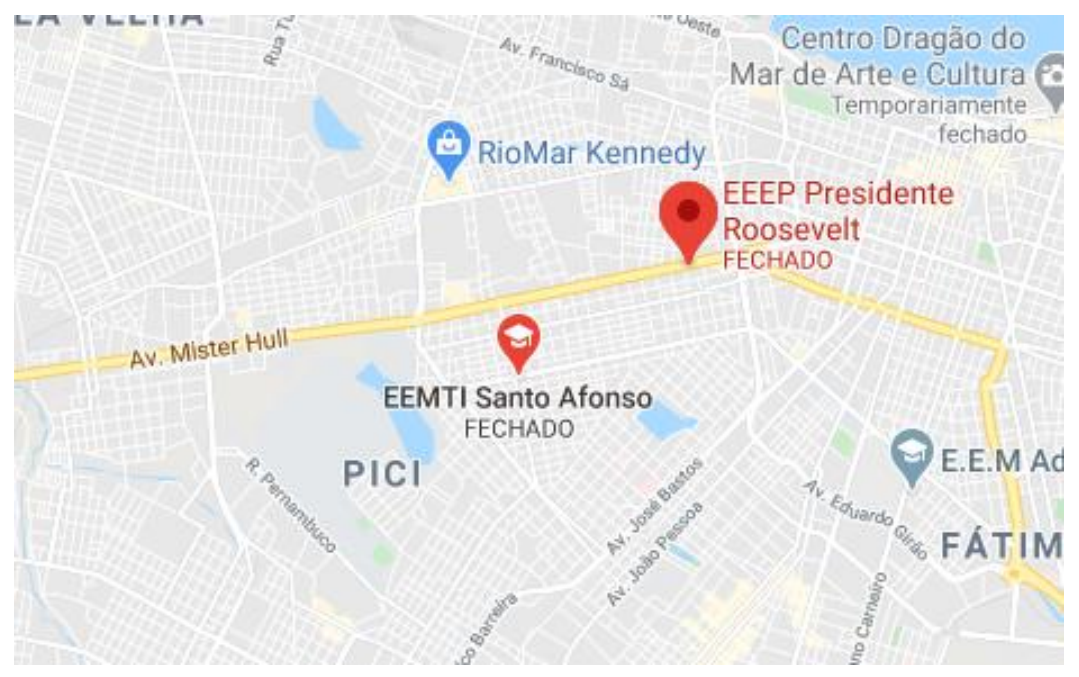

Fonte: (Google Maps, 2020)

\subsection{Palestra nas Escolas}

Esta parte da ação consistia em realizar as palestras nas escolas, com duração de 50-90 min, nas quais foi explanado o desenvolvimento das atividades do projeto nos últimos anos e diversas oportunidades que a Universidade Federal do Ceará proporciona aos seus alunos, dentre elas: bolsas de iniciação científica, de ensino e de extensão, bolsas de desporto, restaurante universitário, assistência em saúde, ônibus para circular dentro da universidade e cursos de idiomas.

Antes do encerramento de cada palestra, os alunos foram orientados a realizar a avaliação do projeto e a inscrição no minicurso na plataforma digital e, também, sobre os horários e como seriam as atividades do minicurso de "Noções de Topografia e suas Aplicações", ofertadas aos mesmos. As figuras 2 e 3 apresentam foto das palestras nas escolas. 


\section{COBENCE de Educação em Engenharia da ABENGE}

"Os desafios para formar hoje o engenheiro do amanhã"

Figura 2 - Palestra realizada na EEEP Presidente Roosevelt.

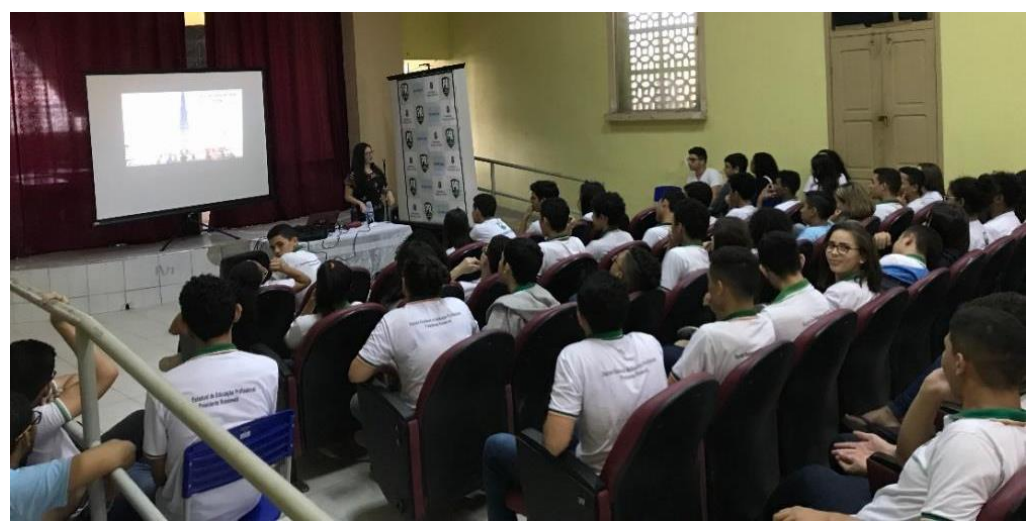

Fonte: Autores.

Figura 3 - Palestra realizada na EEMTI Santo Afonso.

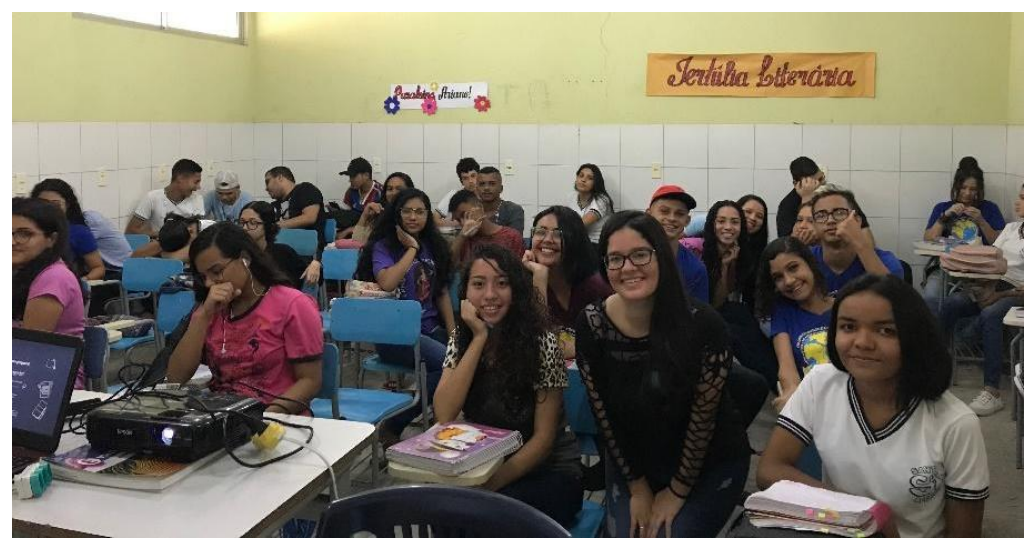

Fonte: Autores.

\subsection{Minicurso: "Noções de Topografia e suas Aplicações"}

Após a inscrição via formulário online, o minicurso "Noções de Topografia e suas Aplicações" foi realizado em dois sábados para cada turma, de $8 \mathrm{~h}$ às $13 \mathrm{~h}$, totalizando 10 horas, gerando certificado ao final. O minicurso acontece no Laboratório de Geomática Aplicada (LAG), localizado no Centro de Tecnologia, no bloco 717.

Os alunos foram divididos em três turmas de 23 alunos. No primeiro sábado foi abordado o assunto de Planimetria e no segundo o de Altimetria, sendo aplicados dois questionários, um em cada dia.

\section{Aula 1}

Inicialmente, no primeiro sábado de minicurso, foi aplicado um questionário sobre assuntos de Matemática e Geografia que os alunos provavelmente já haviam visto durante sua vida escolar.

Neste dia foram abordados assuntos sobre a Topografia no geral e sua divisão, com maior foco na Planimetria; apresentação dos equipamentos utilizados nos levantamentos; e, explicação sobre o levantamento topográfico e sua importância. Em seguida, dividiu-se a turma em equipes de no máximo 5 pessoas e realizou-se a prática em campo, com um levantamento planimétrico em três pontos identificados, previamente, pela equipe do laboratório. Foi ensinado o processo de montagem do equipamento topográfico, utilizando de Estação Total RTS R3 Ruíde, Prisma e Tripé como mostram as Figuras 4 e 5. 
Figuras 4 e 5 - Participantes operando a Estação Total.
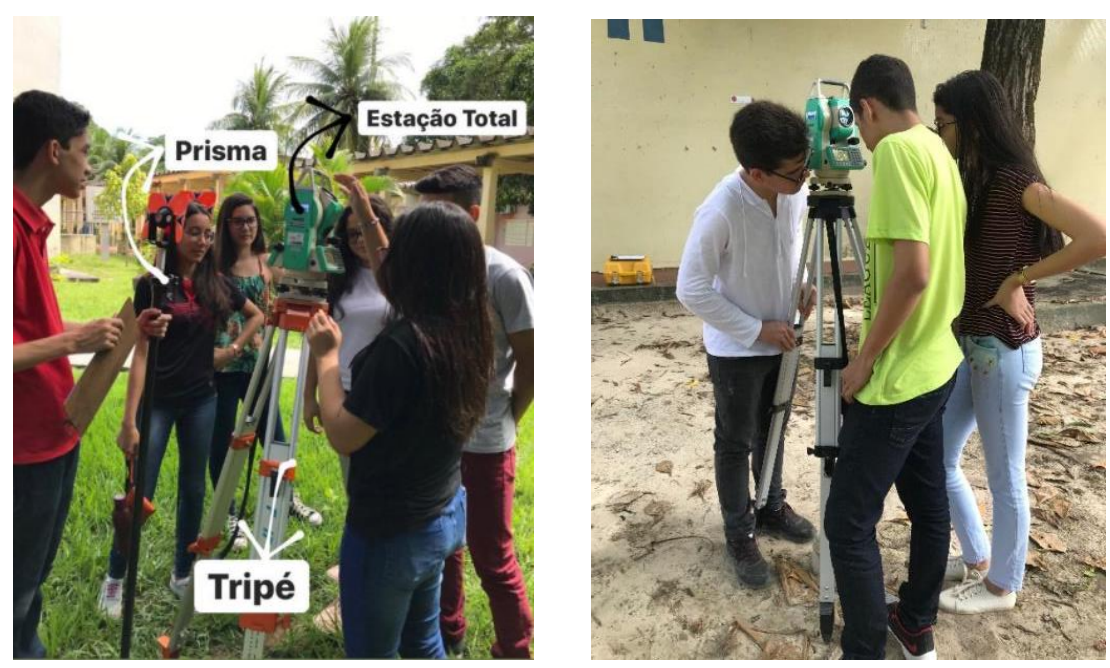

Fonte: Autores.

\section{Aula 2}

O segundo dia de aula do minicurso foi iniciado com a introdução teórica sobre levantamento altimétrico, na qual se abordou a definição de altimetria e o que são referências de nível; conceito de altitude e cota; tipos de nivelamento e os equipamentos utilizados para a realização desse tipo de nivelamento.

Em seguida, os participantes foram levados ao campo para realizarem um levantamento geométrico composto, utilizando o Nível Digital DL-201, Ruíde, com sua respectiva régua com código de barras e tripé específicos, como mostram as Figuras 6 e 7.

Figuras 6 e 7 - Participantes operando o Nível Eletrônico.
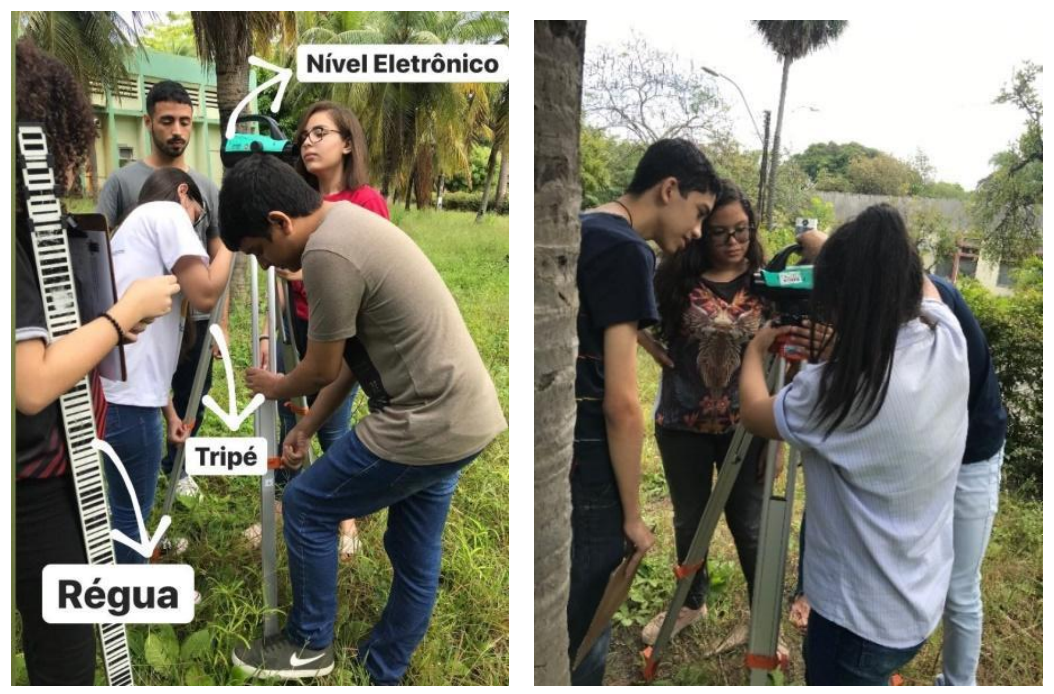

Fonte: Autores. 
C COBENCE 2020 (1)

"Os desafios para formar hoje o engenheiro do amanhã"
$\mathrm{Ol}$ a $\mathrm{O3}$ de dezembro Evento On-line

Ao final do minicurso foi passado um questionário para avaliar o conhecimento adquirido pelos alunos nos dois dias de aula e lhes foi entregue o certificado. A figura 8 mostra os alunos de uma turma com os certificados.

Figura 8 - Participantes da Primeira Turma com os Certificados.

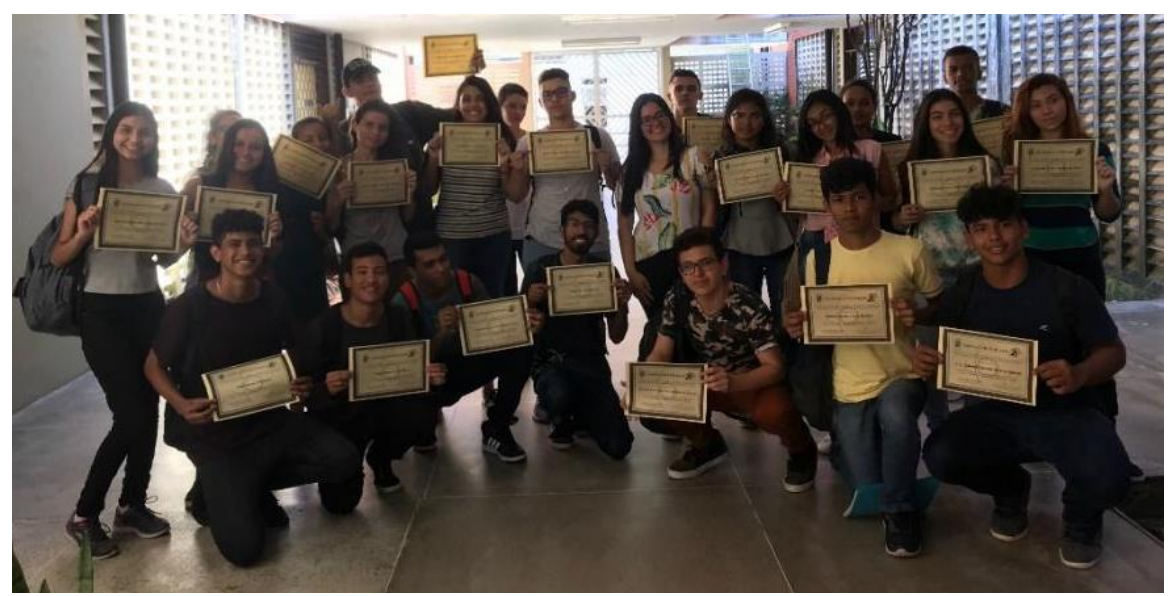

Fonte: Autores.

\section{RESULTADOS E DISCUSSÃO}

No mesmo formulário de inscrição, os alunos deveriam avaliar a palestra ministrada em suas escolas, o resultado está no gráfico 1. A palestra foi bem avaliada, com $100 \%$ avaliando de bom a excelente.

Gráfico 1: Avaliação da palestra nas escolas.

\section{Avaliação da Palestra nas Escolas}

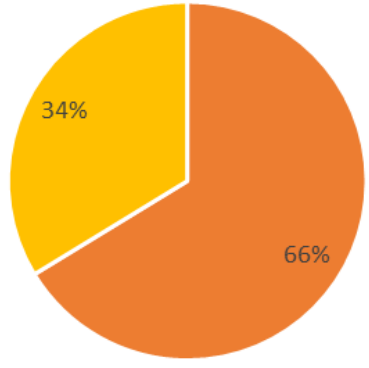

- Excelente $=$ Boa

Fonte: Autores.

No primeiro dia de minicurso, foi aplicado um questionário para saber como estava o conhecimento dos alunos participantes acerca de conteúdos de Matemática e Geografia. O Gráfico 2 mostra o desempenho das turmas segundo o questionário. 


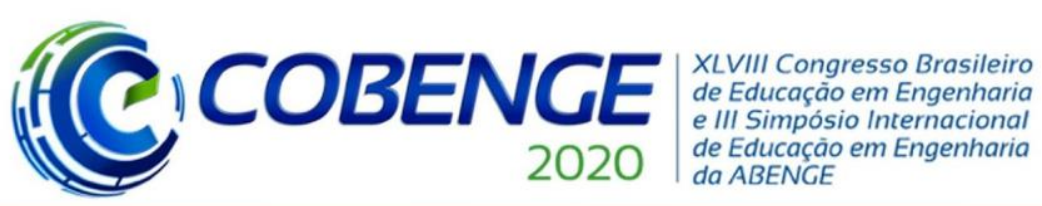

"Os desafios para formar hoje o engenheiro do amanhã"
$\mathrm{O}$ a $\mathrm{O3}$ de dezembro Evento On-line

Gráfico 2 - Desempenho das Turmas no Questionário 1.

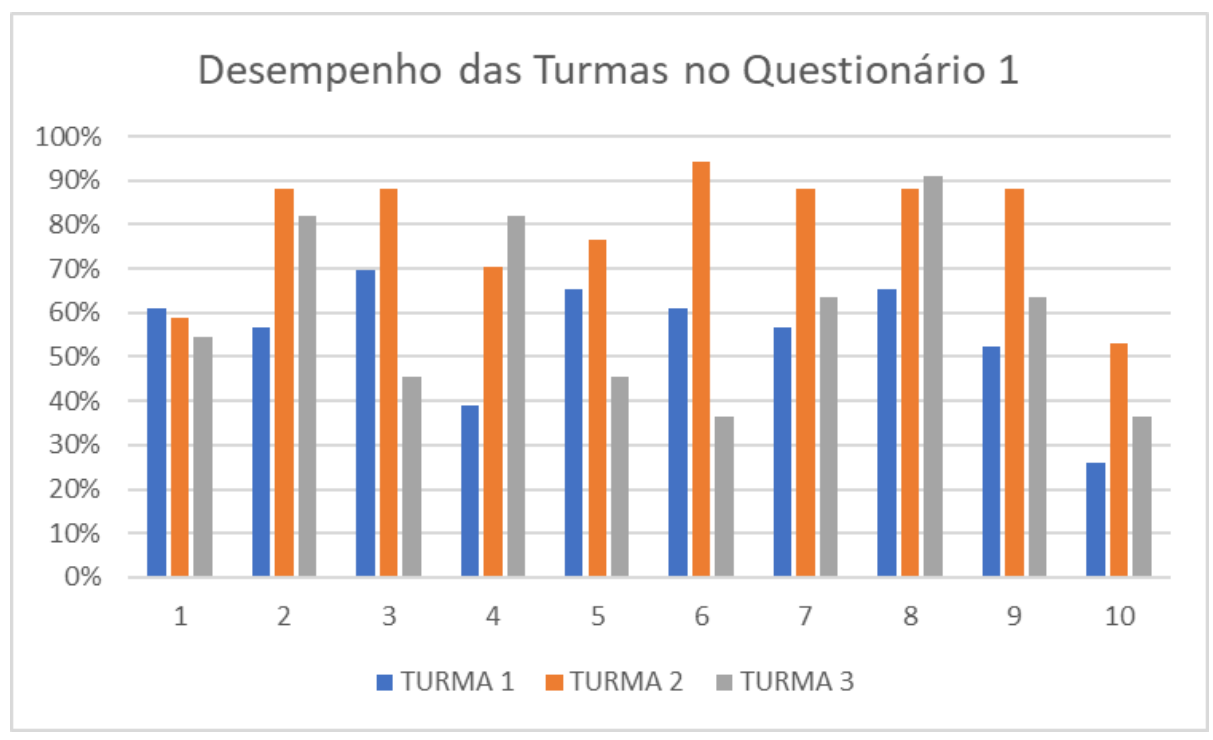

Fonte: Autores.

Observa-se que a turma 2 obteve o maior êxito em relação às outras, com a maioria da turma atingindo mais de $70 \%$ de acertos nas questões do teste. A média das turmas foi: 5,47 para a turma $1 ; 8,05$ para a turma 2; e 5,85 para a turma 3 . Resultando em uma média geral de 6,45 .

Ao final do minicurso outro teste foi aplicado para avaliar o quanto os alunos conseguiram absorver durante o minicurso, resultando no gráfico 3.

Gráfico 3 - Desempenho das Turmas no Questionário 2.

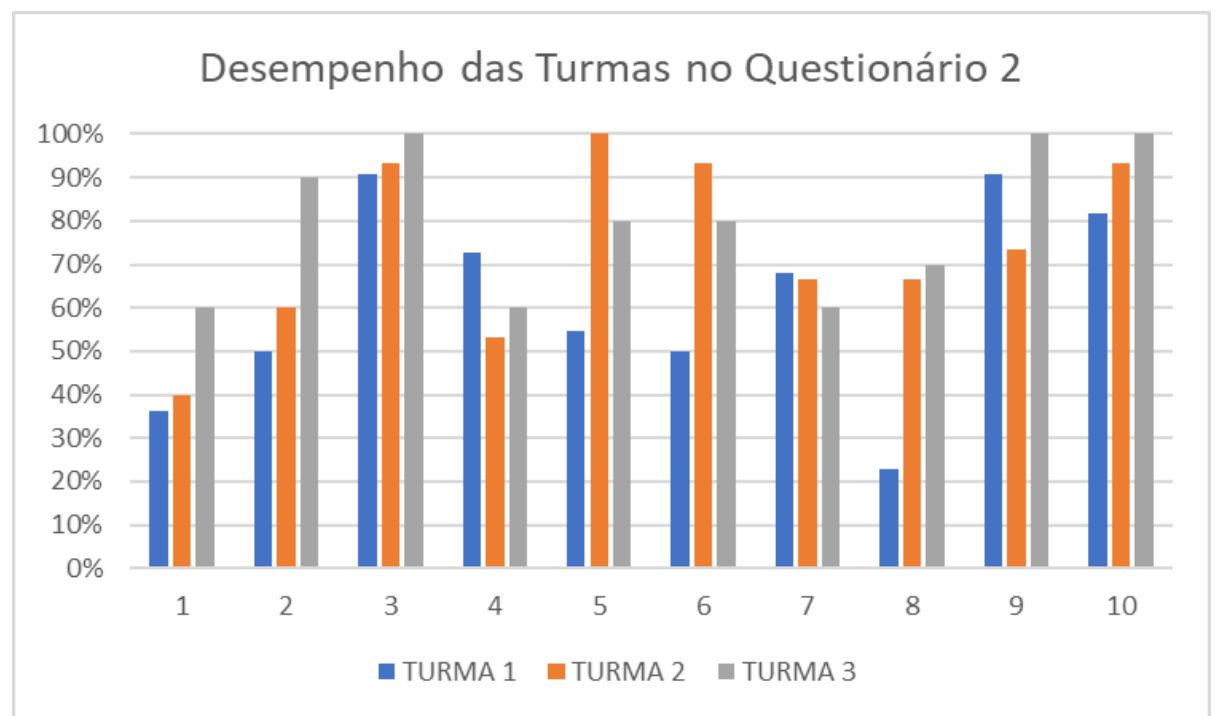

Fonte: Autores.

Nota-se uma melhora no resultado das três turmas, havendo até $100 \%$ de acerto em algumas questões. A média das turmas foi: 6,15 para a turma $1 ; 7,48$ para a turma 2 ; e 7,70 para a turma 3. Resultando em uma média geral de 7,11, havendo uma melhora de forma geral.

Ao final do projeto, pediu-se que os alunos avaliassem o minicurso e também as 


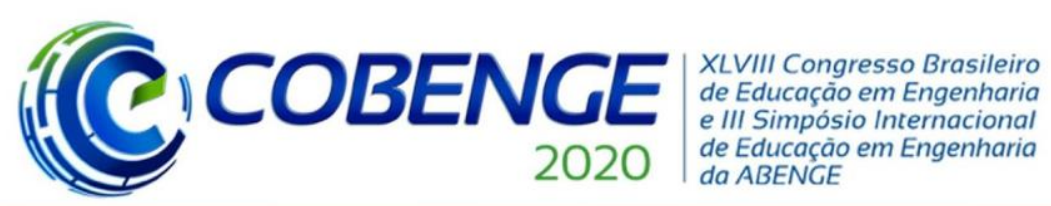

"Os desafios para formar hoje o engenheiro do amanhã"
$\mathrm{Ol} \mathrm{a} \mathrm{O3}$ de dezembro Evento On-line

instalações do Laboratório de Geomática Aplicada (LAG), onde acontece o minicurso. Os resultados estão nos gráficos 4 e 5 .

Gráficos 4 e 5 - Avaliação do Minicurso e das Instalações do Laboratório.

Avaliação do Minicurso de Topografia

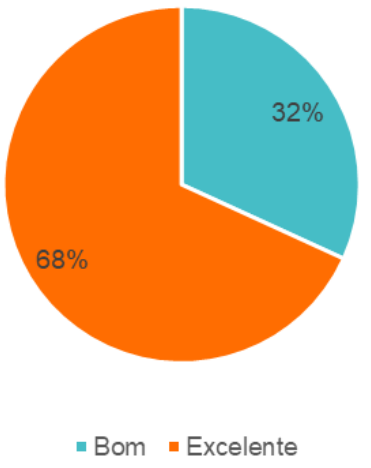

Avaliação dos Alunos quanto às Instalações do Laboratório

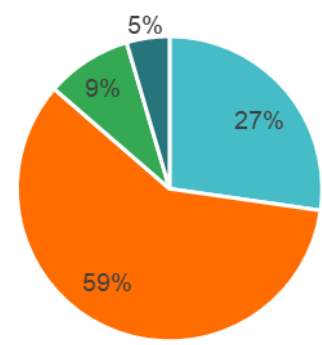

- Boa =Excelente " Regular - Ruim

Fonte: Autores.

Observa-se que o minicurso foi bem avaliado pelos alunos, alguns pediram até que tivesse uma duração mais longa. Ainda, a estrutura do laboratório foi bem avaliada também, cerca de $86 \%$ variando de excelente a boa.

O gráfico 6 apresenta a influência do minicurso na futura escolha profissional dos alunos, o qual mostrou que para até $64 \%$ dos alunos, o minicurso foi bastante influente.

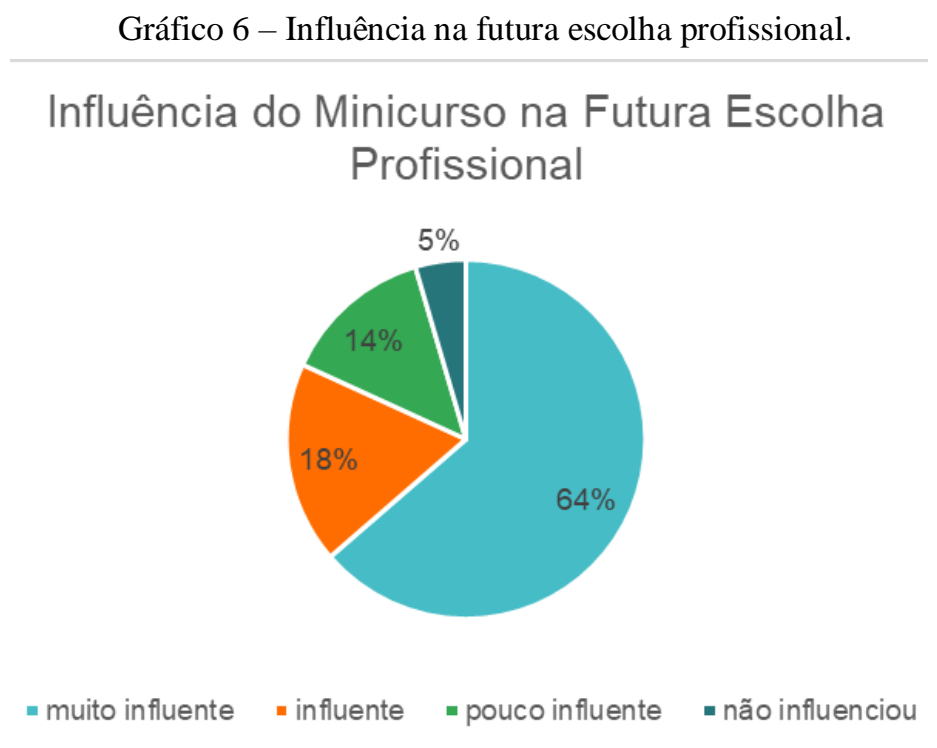

Fonte: Autores. 


\section{CONSIDERAÇÕES FINAIS}

Com a realização desse projeto, foi possível proporcionar momentos de integração e aprendizado aos possíveis futuros discentes da Universidade Federal do Ceará.

A disciplina de Topografia permite aliar a teoria com a prática, facilitando o aprendizado e tornando-o mais efetivo, visto que além de estudarem na sala os conteúdos de planimetria e altimetria, os alunos puderam manusear os equipamentos utilizados para realizar levantamentos topográficos.

De acordo com os alunos, o minicurso influenciou bastante na escolha profissional de cada um deles, sendo possível incentivá-los a escolher a Engenharia Civil como futura profissão. A vida profissional e pessoal dos monitores do projeto é impactada positivamente, visto que há o aprimoramento de habilidades que não são da grade curricular do curso de Engenharia Civil, a exemplo da oratória e de soft skills, como liderança e gestão de equipes. Essas habilidades são bastante desenvolvidas em projetos de extensão, pois há uma troca de experiências entre os alunos da Universidade Federal do Ceará com os alunos das escolas públicas.

Os alunos puderam conhecer mais sobre a UFC e sobre as oportunidades que ela oferece. $\mathrm{O}$ projeto foi bem avaliado e alguns alunos até pediram que o minicurso tivesse uma maior duração.

\section{Agradecimentos}

À Universidade Federal do Ceará pelo fomento através da pró-reitoria de extensão, com bolsa cedida aos alunos, ao Laboratório de Geomática Aplicada pelo apoio, às escolas participantes da atividade de extensão e ainda, aos alunos que se interessaram em fazer parte do projeto.

\section{REFERÊNCIAS}

\section{Livros:}

DAGNINO, R.; NOVAES, H. T.; FRAGA, L. O engenheiro e a Sociedade: Como transformar a sociedade de classes através da ciência e tecnologia. Florianópolis: Insular, 2013.

FREIRE, Paulo. Pedagogia da Autonomia: saberes necessários à prática educativa. 25. ed. São Paulo: Paz e Terra, 2002. 54 p. Disponível em: http://www.apeoesp.org.br/sistema/ck/files/4-

\%20Freire_P_\%20Pedagogia\%20da\%20autonomia.pdf. Acesso em: 01 jun. 2020.

NUNES, A.L. P. F.; SILVA, M. B. C. A extensão universitária no ensino superior e a sociedade. Mal-Estar e Sociedade, v. Ano IV, p. 119-133, 2012.

\section{Monografias, dissertações e teses:}

OLIVEIRA, Victor Cardoso. Engenharia na Escola: a disciplina de topografia como meio aproximador entre os ensinos médio e superior. 2018. Trabalho de Conclusão de Curso (Graduação) - Centro de Tecnologia, Universidade Federal do Ceará, Fortaleza, 2018.

\section{Entidades:}

Ideb- Índice de Desenvolvimento de Educação Básica. Ideb tem pequeno avanço no ensino 
"Os desafios para formar hoje o engenheiro do amanhã"

médio, mas segue abaixo da meta. Brasília (DF); 2018

Artigo em revistas:

LEWIN, A.M.F. e LOMASCÓLO, T.M.M. La metodologia científica em la construcción de conocimientos. Enseñanza de las Ciencias. Revista Brasileira de Ensino de Física, São Paulo, v. 20, n.2, p. 147-154, 1998.

TOZZI, M. Escolha da Profissão. Revista Engenharia e Construção, nº ${ }^{\circ}$ 88, p. 10 e 11, janeiro de 2004.

Normas:

BRASIL. Lei No 9.394, de 20 de dezembro de 1996: Leis de Diretrizes e Bases da educação Brasileira (LDB), Brasília, 1996.

\title{
APROACH OF THE CT TO THE PUBLIC SCHOOLS SURROUDING PICI THROUGH THE TEACHING OF TOPOGRAPHY
}

\begin{abstract}
The extension project "Engineering in the School" was created in order to bring to the Technology Center students from public schools in the surrounding of the Pici Campus, making them able to get know one of the Federal University of Ceara campuses. This approach takes place through the discipline of Topography, of the Civil Engineering course, since it addresses the contents of Mathematics and Geography, learned during school life. Two schools were selected in 2019, with three classes being formed with students interested in participating in the short course "Notions of Topography and its Applications". Initially, a lecture was held in each school, in which opportunities and the courses offered by the university were explained, in addition to their distribution on campuses. Then, classes are formed for the short course and in which two questionnaires are applied, one on the first day and another on the second, in order to assess the knowledge acquired by the participants. The results showed that the students were able to relate the content addressed in the short course with those who had already been studied during their school life, thus being well evaluated by the participants.
\end{abstract}

Keywords: Engineering, approach, topography, teaching, extension. 